\title{
PERCEPÇÃO DE GRADUANDOS DE ENFERMAGEM ACERCA DO PROCESSO DE ENSINO-APRENDIZADO DAS TEORIAS DE ENFERMAGEM
}

\author{
Ângela Lima Pereira ${ }^{1}$ \\ Tony Augusto Serejo Sousa ${ }^{2}$ \\ Eunice Cabral Lima $^{3}$ \\ Adriana Lima Pereira ${ }^{4}$ \\ Wender Lopes Rezende ${ }^{5}$ \\ Daiana Bueno Ribeiro ${ }^{6}$
}

\begin{abstract}
Resumo - Trata-se de um estudo descritivo-exploratório, de caráter qualitativo, sobre o ensino-aprendizado das teorias de enfermagem que teve como objetivo geral conhecer a percepção de um grupo de graduandos de enfermagem acerca da sua experiência no processo de ensino/aprendizagem das teorias de enfermagem; constando de 10 estudantes do Curso de Enfermagem, homens e mulheres, que cursaram a disciplina de Sistematização da Assistência de Enfermagem na qual é ministrado o tema teorias de enfermagem. Os dados coletados geraram três grandes categorias, que posteriormente foram subdivididas em subcategorias que emergiram de cada uma destas, como: "Significado das Teorias de Enfermagem", "Facilidades Vivenciadas Processo de Ensino-Aprendizado das Teorias de Enfermagem", "Dificuldades Vivenciadas Processo de EnsinoAprendizado das Teorias de Enfermagem". Neste trabalho encontramos algumas falas do grupo de acadêmicos pesquisados que nos remetem a uma rápida reflexão sobre a formação profissional frente às premissas já amplamente abordadas por outros pesquisadores. $\mathrm{O}$ referente estudo instigou algumas discussões sobre o ensino das teorias de enfermagem para acadêmicos do curso de graduação; desenvolver outros estudos, em realidades diferentes, pode ampliar o conhecimento sobre a visão dos alunos acerca do processo de ensino-aprendizado desta temática, e contribuir para um entendimento maior sobre o mesmo, além de fornecer elementos que favoreçam a identificação de melhores estratégias de ensino.

Palavras chaves: Ensino-aprendizado, Teorias de enfermagem, Percepção, graduando de enfermagem.
\end{abstract}

\footnotetext{
Abstract - This is a descriptive exploratory study, qualitative, on the teaching-learning of nursing theories that aimed to understand the perception of a group of undergraduate nursing students about their experience in the teaching / learning of nursing theories, consisting of 10 students of nursing, men and women who were enrolled in the discipline of Nursing Care System in which the subject is taught nursing theories. The collected data yielded three major categories, which were then divided into subcategories that emerged from each of these, such as: "Meaning of Nursing Theories," "easily experience the Teaching-Learning of Nursing Theories,"

Enfermeira. Professora do Curso de Enfermagem da Universidade Federal de Goiás Campus Jataí. Email: angelimap@gmail.com

2 Enfermeiro do Corpo de Bombeiros Militar de Goiânia - Goiás E-mail: augusto.serejo@hotmail.com

Pedagoga da Secretaria Estadual de Educação de Rondônia. E-mail: eunicecabral.lima@,gmail.com

Professora Licenciada em Educação Física Escolar, da Escola Estadual Duca Viggiano, Goiânia -

Goiás. E-mail: luaespelho@gmail.com

Acadêmico do Curso de Enfermagem da Universidade Federal de Goiás - Campus Jataí. E-mail:

wenderlopesbio@hotmail.com
} 
"Difficulties experienced Process Teaching-Learning of Nursing Theories. " In this work we find some statements of the group of academics surveyed leading us to a quick reflection on the training front of the premises already widely discussed by other researchers. The referent study prompted some discussion about the teaching of nursing theories to students of undergraduate, developing other studies in different realities, may extend the knowledge of students' views about the teaching and learning of this topic, and help a greater understanding of the same, and providers to encourage the identification of best teaching strategies. Keywords: Teaching and Learning, Theories of nursing, Perception, the nursing student.

\section{INTRODUÇÃO}

Teoria pode ser conceituada como "o princípio de uma arte ou ciência"; ainda, como "uma abstração sistemática da realidade, elaborada para um propósito específico". As teorias de enfermagem contribuem na prática profissional do enfermeiro, por oferecer elementos para pensar a assistência, "evidenciando seus propósitos, limites e relações entre profissionais e indivíduos que cuidam e são cuidados" (CHINN, 1995). Assim, as teorias de enfermagem são imprescindíveis no trabalho profissional do enfermeiro, constituindo a base estrutural para a orientação no processo de enfermagem.

Uma teoria não precisa ser utilizada isoladamente, sendo possível realizar a combinação de mais do que uma teoria para pensar a prática assistencial de enfermagem (STANTON, 1993). Desta forma, diferentes instrumentos de coleta de dados têm sido desenvolvidos com base em uma ou mais teorias de enfermagem, e que norteará o trabalho do enfermeiro na sua prática assistencial. Em nossa realidade de trabalho, temos utilizado um instrumento de coleta de dados construído com base em quatro teorias: teoria da diversidade e universalidade transcultural do cuidado, de Madeleine Leininger; teoria do autocuidado, de Dorothea E. Orem; teoria da adaptação, de Callista Roy; e teoria ambientalista de Florence Nightingale.

É possível que o enfermeiro, ao utilizar de forma coerente às teorias na prática assistencial, possa identificar aquelas nas quais sente maior confiança. Estes podem, ainda, descobrir que algumas teorias funcionam melhor em certas situações do que em outras, por meio de relatos escritos precisos, e pela comunicação entre os profissionais do sucesso ou fracasso. Isso contribui para que a prática da enfermagem torne-se mais eficiente e realista (MARRINER-TOMEY, 1994).

É comum ouvir relatos de enfermeiros e alunos do curso de enfermagem, em relação às dificuldades encontradas durante o processo de aprendizado das teorias, e relacioná-las durante a prática clínica. Martins, Gomes e Nishimura (2004), em estudo que buscou 
conhecer a percepção de discentes de enfermagem acerca das teorias de enfermagem, identificaram dificuldades semelhantes às vivenciadas em nosso meio. As autoras afirmam que o tipo de formação profissional influencia na tomada de decisão do profissional. Assim, é importante que os profissionais de saúde educadores, envolvidos no processo de ensinoaprendizado das teorias de enfermagem, estejam comprometidos com esse processo e busquem sempre melhores estratégias a serem utilizadas durante as aulas.

É importante, ainda, que mais estudos sejam realizados no sentido de buscar conhecer os fatores que interferem no processo de ensino-aprendizado das teorias de enfermagem, bem como as melhores estratégicas de ensino que têm sido utilizadas com sucesso, em diferentes realidades de trabalho. Compartilhar estas informações é imprescindível para o avanço do conhecimento nesta área temática.

Compreender a percepção do graduando de enfermagem acerca da sua experiência no aprendizado das teorias de enfermagem é fundamental para que professores e alunos, envolvidos nesse processo, possam refletir sobre o tema e identificar estratégias para melhorias no processo de ensino-aprendizado das teorias de enfermagem. Esta reflexão poderá, também, gerar novas questões de pesquisa.

Desta forma, este estudo teve como objetivo geral conhecer a percepção de um grupo de graduandos de enfermagem acerca da sua experiência no processo de ensino/aprendizagem das teorias de enfermagem. Ainda, como objetivos específicos: identificar os fatores facilitadores e os que têm dificultado o processo de ensino/aprendizagem das teorias de enfermagem, vivenciado por um grupo de graduandos de enfermagem; pontuar os fatores que dificultaram o seu processo de ensino/aprendizagem das teorias de enfermagem.

\section{MATERIAIS E MÉTODOS}

\section{Tipo e local do estudo}

Tratou-se de um estudo descritivo-exploratório, de caráter qualitativo, que foi realizado em uma Universidade Privada, em Goiânia, Goiás.

\section{População}


Constou de 10 estudantes do Curso de Enfermagem, homens e mulheres, que cursaram a disciplina de Sistematização da Assistência de Enfermagem na qual é ministrado o tema teorias de enfermagem.

Uma vez que a pesquisa qualitativa "não se baseia em critérios numéricos para garantir sua representatividade" (Minayo, 1994, p.43), não foi determinada a priori o tamanho exato da amostra, sendo esta definida, posteriormente, pela saturação dos dados.

Durante a seleção da amostra foram adotados os seguintes critérios de inclusão: ser maior de 18 anos, estudante do curso de enfermagem da Universidade na qual o estudo estava sendo realizado, ter concluído a disciplina de Sistematização da Assistência de Enfermagem, e fornecer autorização formal, por meio da assinatura escrita do Termo de Consentimento Livre e Esclarecido - TCLE.

Ainda, foram adotados os seguintes critérios de exclusão: ser menor de 18 anos, aluno do curso de Enfermagem em outra Instituição de Ensino Superior, não ter cursado/concluído a disciplina de Sistematização da Assistência de Enfermagem, não fornecer o consentimento para participar do estudo, por meio da assinatura escrita do TCLE; e/ou sentir-se desconfortável com a pesquisa, em qualquer momento desta, ou desejar retirar sua participação.

\section{Procedimentos éticos}

Este projeto foi encaminhado à Coordenação do Curso de Enfermagem da Universidade na qual o estudo foi realizado, para apreciação e consentimento à realização do mesmo. Em seguida, foi submetido ao Comitê de Ética em Pesquisa da Universidade Salgado de Oliveira - Campus Rio de Janeiro. Após parecer favorável, Protocolo $n^{\circ} 49 / 2008$, os sujeitos deste estudo foram abordados pelos pesquisadores, que lhes forneceram informações referentes à pesquisa, e solicitaram permissão para sua participação, por meio da assinatura escrita do TCLE, conforme as leis vigentes (BRASIL, 1996).

\section{Procedimento de Coleta e Análise de Dados}

A coleta de dados foi realizada por meio de entrevista gravada, após permissão dos sujeitos, e direcionada por um roteiro com as seguintes questões de discussão: 1. O que significa para você as teorias de enfermagem? 2. Comente os fatores que julga ter contribuído 
e facilitado no seu aprendizado das teorias de enfermagem. 3. Comente sobre os fatores que julga ter dificultado o seu aprendizado no das teorias de enfermagem. Posteriormente, as entrevistas foram transcritas na íntegra e analisadas à luz do referencial metodológico de Análise de Conteúdo, proposto por Minayo (1994).

\section{RESULTADOS}

As questões de discussão geraram três grandes categorias, que posteriormente foram subdivididas em subcategorias que emergiram de cada uma destas. As categorias maiores foram nomeadas como: "Significado das Teorias de Enfermagem", "Facilidades Vivenciadas Processo de Ensino-Aprendizado das Teorias de Enfermagem", "Dificuldades Vivenciadas Processo de Ensino-Aprendizado das Teorias de Enfermagem".

\section{Significado das Teorias de Enfermagem}

- Teoria de Enfermagem como Guia à Prática Assistencial

Quando questionados sobre sua visão acerca dos significados das teorias de enfermagem, alguns alunos apresentaram o significado relacionado à prática assistencial, como um guia para melhorias na qualidade da assistência da enfermagem, e sistematização da assistência.

Sujeito 1. "prestar uma assistência melhor"... "é a sistematização..."

Sujeito 2. "serve de direcionamento para os profissionais de enfermagem de hoje, não só para elas (as teoristas)"... “abrangem bem a assistência de enfermagem de uma forma geral"

Sujeito 3. "é fundamental para todo o processo de enfermagem"... "é a base, o alicerce para que o enfermeiro venha desenvolver um novo processo (de enfermagem)... "adaptá-las à nossa realidade"... "para melhoria da nossa profissão"...

Sujeito 6. “... as teorias de enfermagem servem como referência... base para o tratamento do paciente..."

Sujeito 8. “... serve de guia... direcionamento de como tratar um paciente... serve para guiar o comportamento do enfermeiro no tratamento do paciente...”

- Conhecimento Específico em Enfermagem 


\section{itherarius Reflectionis}

vol. 2 n.9 2010

O significado, das teorias de enfermagem, também foi apresentado associado ao desenvolvimento de um conhecimento específico de enfermagem, e imprescindível á prática assistencial.

Sujeito 2. "um conjunto de experiências acumulados no decorrer da evolução da própria enfermagem enquanto profissão"

Sujeito 4. "visão... a base da enfermagem... como atuar como enfermeiro"... o porquê de existir a enfermagem"..." todas elas (as teorias) vão fornecer o conteúdo (conhecimento) pra gente atuar..."

Sujeito 5. "de extrema importância pra gente ter conhecimento de como surgiu, de como é, por que... como se fosse um conselho bom... dentro da enfermagem... cada uma das teorias... importante pra poder ter entendimento da prática, dia-a-dia da enfermagem...

Sujeito 8. “... mostra o caráter científico da profissão...

\section{- Imagem da Enfermagem}

Houve, ainda, a associação das teorias de enfermagem com a imagem que os alunos têm acerca da enfermagem enquanto categoria profissional.

Sujeito 2. "é a cara da enfermagem"

Sujeito 7. “... marcaram a história... (da enfermagem)”

\section{Facilidades vivenciadas no processo de ensino-aprendizado das teorias de} enfermagem

De forma geral, os alunos apontaram dois fatores como facilitadores do processo de ensino-aprendizado das teorias de enfermagem. O primeiro está diretamente relacionado às estratégias utilizadas pelos professores ao abordar o tema, e o segundo está relacionado às características do próprio professor da disciplina.

\section{- Estratégias utilizadas}

As principais estratégias apontadas como facilitadoras, foram: apresentação prévia de textos de apoio, discussão em grupo, seminários, orientação direta na preparação dos seminários/trabalhos, uso de recursos audiovisuais durante as aulas, utilização de estudos de caso. Estes dados podem ser evidenciados nas falas abaixo:

Sujeito 1. "o que facilitou foi ela (a professora) ter trazido texto para ler"... discutiu... entre o grupo" 
Sujeito 3. "foi muito válido, até mesmo porque na época em que fiz (a disciplina) nós tivemos muitos seminários"

Sujeito 4. "a professora orientou o trabalho, o que ela queria daquele trabalho... e também comentou em cada trabalho, o que foi visto, o que era importante... porque aquilo era importante durante nossa vida profissional né... isso foi a diferença, uma (sua primeira professora) deu como uma disciplina qualquer, pra você ganhar nota e complementar seu currículo, e a outra (segunda professora) deu como uma disciplina para você atuar e trabalhar como enfermeira."

Sujeito 5. "pra melhor entender foi o seminário, eu acho que foi de extrema importância em questão de aprendizagem, porque a gente pôde realmente parar pra ler... às vezes a gente não para pra prestar atenção e ver como é que é, no caso do seminário a gente estudou, pesquisou e começou a despertar curiosidade pra entender...

Sujeito 6. “... exposição com uso de recurso audiovisual... seminários e teatro... um grupo fez um teatro, claro que a criatividade do aluno favoreceu né, para o aprendizado..."

Sujeito 7. “... a estratégia que ela utilizou na sala. Ela dava um texto de apoio, a gente lia, chegava na sala, a gente discutia...."

Sujeito 8. “... grupos que apresentaram... estudos de caso clínico também... foram bastante produtivos..."

\section{- Intimidade do professor com o tema}

Sujeito 2. "a postura"... (da professora) "era muito bonito"... "ela falava com paixão"...

Sujeito 4. "como passar... trazendo, fixando a importância... isso deixa a pessoa cada vez mais curiosa de saber o porquê, como foi... como melhorou a enfermagem... te enriquece..."

Sujeito 6. “... a exposição da professora... ela passou... de maneira clara... facilitou bastante..."

Sujeito 8. "a questão da vontade do professor em passar pra todos os alunos o que é realmente..."

Dificuldades vivenciadas no processo de ensino-aprendizado das teorias de enfermagem

Quanto aos fatores que dificultaram o processo de ensino-aprendizado das teorias de enfermagem, os alunos apontaram algumas referentes à disciplina em si: carga horária 
reduzida, e o horário em que a disciplina foi disponibilizada aos alunos, posterior a outra disciplina considerada por estes como sendo “pesadas" (Sujeito 3).

- A carga horária reduzida

Sujeito 1. "precisava ter mais aulas"

Sujeito 2. "é insuficiente, eu acho que deixa com gostinho de quero mais..." "muito conteúdo"... "eu acho que poderia ter trabalhado em uma carga horária bem maior"

\section{- Horário da disciplina}

Sujeito 3. "o horário que fiz... nós tínhamos acabado de fazer a matéria de fisiologia... já estava com a cabeça cheia... se fosse um horário mais cedo... um dia único... seria mais proveitoso..."

Outro fator esteve diretamente relacionado às competências do professor que ministrou a disciplina, no que ser refere às estratégias utilizadas por este.

- Estratégias de ensino

Sujeito 1. "ela (a professora) poderia ter discutido mais na sala de aula... mais questionários e seminários..."

Sujeito 4. "a primeira vez que fiz (a disciplina) achei muito vago, a professora só falava, falava... e não fazia nada (exemplos)... então achei ruim... achei até que não serviria de nada..."

Sujeito 7. “... ela poderia ter usado mais vídeos, ter trazido mais pessoas com vivências em certas áreas... poderia ter uma participação maior entre ela e a professora de estágio pra gente poder aplicar as teorias no estágio...”

Fatores relacionados aos alunos também foram amplamente discutidos, sendo categorizados como "maturidade do aluno", e "tempo para o estudo".

- Maturidade do Aluno

Sujeito 5. “.... dificuldade que tive mesmo foi, acho que minha, porque deveria ter dedicado mais talvez... ter tido mais curiosidade... eu sei que daqui pra frente vou começar a ter mais curiosidade pra poder voltar naquilo... que não tive entendimento antes..." 
Sujeito 6. "no $3^{\circ}$ período, assim, você não tem tanta noção da matéria... se o aluno tivesse mais amadurecimento.... isso é um fator negativo..."

Sujeito 7. “... eu não pensava que as teorias... fosse tão importante no final do curso... procurei estudar somente pra passar naquela matéria e não trazer pra vida. A hora que chegou no $8^{\circ}, 7^{\circ}$ período (do curso) eu percebi o que tinha perdido. Tinha que aproveitar mais."

Sujeito 8. “... a questão do desinteresse dos alunos... porque a sistematização pra mim, no $3^{\circ}$ período é inadequada. Acredito que deveria ser visto no $5^{\circ}$ e $6^{\circ}$ período ou até mesmo no $7^{\circ}$ período..."

\section{- Tempo para o Estudo}

Sujeito 7. "quando eu fiz a disciplina, eu estava em dois empregos... sempre estava dormindo na sala, matei o limite das aulas... estava passando dificuldades financeiras, então eu precisava dos dois empregos..."

\section{IV - DISCUSSÃO}

Neste trabalho encontramos algumas falas do grupo de acadêmicos pesquisados que nos remetem a uma rápida reflexão sobre a formação profissional frente a premissas já amplamente abordadas por outros pesquisadores. Não iremos nos deter em conceitos sobre teorias de aprendizagem ou teorias metodológicas do processo ensino aprendizagem. A reflexão que fazemos está baseada principalmente nas idéias da pedagogia problematizadora e transformadora, logo, libertadora, de Paulo Freire e na concepção interacionista da aprendizagem. Para Freire (2003),

“... o educador já não é o que apenas educa, mas o que, enquanto educa, é educado, em diálogo com o educando que, ao ser educado, também educa. Que o pensar do educador somente ganha autenticidade na autenticidade do pensar dos educandos, mediatizados ambos pela realidade, portanto na intercomunicação".

Para Vygotsky, a aprendizagem compreende um processo dialético entre "sujeitos e objetos", o professor media e intervém na relação do aluno com o conhecimento. O aluno “... é um sujeito ativo que em sua relação com o mundo, com seu objeto de estudo, reconstrói este mundo..." (REGO, 1999). 
Também entendemos que a resposta à pergunta a seguir pode dar direcionamento às nossas reflexões: Que profissional queremos formar? Acreditamos que a busca maior deve está centrada na formação de um profissional capaz de, a partir da leitura crítica da realidade em que vai atuar, aplicar os conhecimentos teórico/práticos construídos, “... profissionais flexíveis e críticos, aptos para a inserção em diferentes setores profissionais da sociedade brasileira" (SAUPE, 1993).

Se "a educação tem caráter permanente" (FREIRE, 1983), a construção do profissional de enfermagem também. Essa construção deve acontecer de forma dialógica entre educador/educando, onde todo o conhecimento historicamente acumulado é articulado com a compreensão da realidade presente frente às perspectivas futuras. Neste pensamento, a postura do docente frente à disciplina que ministra deve ser crítica, capaz de possibilitar ao educando fazer a relação entre fatos e dados, permitindo assim a aprendizagem de conceitos e princípios e a compreensão dos mesmos. Por outro lado, os conteúdos procedimentais remetem-nos à necessidade de realização de ações ordenadas voltadas à concretude de um objetivo. Portanto, promover a reflexão critica e incentivar mudanças de atitudes são apenas duas das inúmeras indicações possíveis para a otimização do processo ensino aprendizagem.

O saber científico é o referencial para a prática profissional, porém precisa passar a ser ciência da prática, e prática dinâmica. Significa que o saber científico não deve ser estanque. Que o profissional que se pretende é um SER leitor de teorias e também leitor de realidades; capaz de ressignificar constantemente suas concepções de mundo e de homem; de transformar este saber científico em um saber prático, aplicável a realidades específicas. A reflexão sobre a prática, orientada pelos conhecimentos científicos é que permitirá ao profissional reformular esta prática, num processo de ir e vir.

Freinet (1996) ao falar sobre o ciclo da educação afirmava que:

Se um dia os homens souberem raciocinar sobre a formação dos seus filhos como o bom jardineiro raciocina sobre a riqueza de seu pomar, deixarão de seguir os eruditos que, nos seus antros, produzem frutos envenenados que matam ao mesmo tempo quem os produziu e quem os come. Restabelecerão valorosamente o verdadeiro ciclo da educação: escolha da semente, cuidado especial do meio em que o indivíduo mergulhará para sempre as suas raízes poderosas, assimilação pelo arbusto da riqueza desse meio.

Acreditamos que, na formação acadêmica, também precisamos pensar tal qual o bom jardineiro. Não estamos querendo que se deixem de lado as boas experiências já 
desenvolvidas, nem que nos arrojemos, sem reflexão, por caminhos novos. Mas que possamos nos abrir reflexivamente para o novo, para o inédito.

É preciso estabelecer com exatidão aquilo que se deseja da instituição escolar. Esta tarefa não é obra de uma pessoa, mas sim da articulação da vontade de todos os que conjuntamente assumem a responsabilidade de educar (GANDIN, 1995)

Há que se definir com clareza, em qualquer instituição que se pretenda formadora de profissionais, que tipo de profissional se quer formar e a partir desta macro dimensão, pensar as práticas necessárias a serem desenvolvidas em menor dimensão, o que resultará na escolha dos atores/docentes, metodologias e tecnologias adequadas ao processo ensino aprendizagem, dentre outros fatores.

Ao analisar a fala dos sujeitos pesquisados encontramos três pontos mais evidentes relacionados a facilidades e dificuldades vivenciadas no processo de aprendizagem das teorias de enfermagem: estratégias utilizadas pelos docentes, a intimidade do docente com a disciplina e a maturidade do aluno. Partindo da premissa de que a aprendizagem é uma construção, há que se considerarem os vários aspectos implícitos no processo e que nem sempre obedecem ao que podemos chamar de padrão de normalidade. As contradições, as diferenças, as variações e inovações no aprender estão retratadas nos aspectos apresentados pelos sujeitos alvo da pesquisa.

É interessante observar a ênfase dada aos textos, neste caso representando o conhecimento historicamente acumulado, bem como aos debates, seminários, estudo de caso, o que nos aponta para a reflexão, o diálogo, a socialização de experiências. Mas vale lembrar que não é o método ou a técnica em si que faz a diferença, mas o uso que se faz, é o "como" e o "para que" de cada uma delas.

A variação de ações metodológicas apresentadas, aparentemente, está compatível ao estudo teórico da disciplina, contudo há que se atentar para a forma de desenvolvimento dessas técnicas. A dinâmica desenvolvida pelo docente é que irá determinar o maior ou menor grau de positividade na aprendizagem. Daí aparecerem como fator facilitador e de complicador na fala dos sujeitos.

$\mathrm{Na}$ fala do Sujeito 4 encontramos duas posturas diferentes diante de uma mesma disciplina. Práticas que refletem duas concepções diferentes de educação e de profissional frente à formação que acreditamos ser pretendida pela Instituição, e cujo resultado pode ser observado tanto como fator facilitador quanto complicador da aprendizagem. Quando o sujeito faz essa diferenciação, deixa claro que um docente apenas visava à aferição de "nota", 
enquanto o outro visualizava uma atuação futura do sujeito. Aqui pode está implícito a fator "intimidade com a disciplina", o que pode ser substituído por: comprometimento com a formação do profissional de enfermagem. Se “... o melhor professor, (é) aquele que deixou marcas positivas no crescimento do aluno e que o ajudou a desenvolver-se pessoal $e$ profissionalmente, em direção á autonomia...” (FELTRAN, 2003), há que se refletir não só as práticas desenvolvidas na Instituição, mas a herança deixada com cada profissional formado por ela.

Quando os sujeitos apontam os fatores complicadores da aprendizagem, chama a atenção estar implícito nas falas o "não saber o que fazer", "para que serve”. Cremos que, o cerne da questão aqui, não são métodos ou técnicas. Mas como diz Freinet (1996), a questão é “fazer a criança (o aluno) sentir sede”. Os métodos perdem a eficácia se os alunos não estiverem motivados. Sem motivação, nem mesmo buscarão as razões e o significado que cada informação terá para sua formação profissional. Há que torná-los sedentos. Não esquecer que este é um aspecto que deve ser repensado no início de cada turma: a informação clara sobre a profissão, a importância daquilo que se pretende passar ao acadêmico para o cotidiano do profissional. Um repensar não só de carga horária e a reorganização de grade curricular, embora também favoreçam a melhoria do processo.

Contudo, esta é uma discussão que apenas está começando. Consideramos o universo pesquisado ainda pequeno para a magnitude da problemática levantada, porém este pode ser o início de uma discussão mais ampla em torno do processo ensino aprendizagem do profissional de enfermagem, dentro e fora da Instituição acadêmica.

\section{CONCLUSÃO}

Teorias de Enfermagem não é um tema novo, mas que está em construção assim como a própria enfermagem enquanto ciência (GEORGE, 2000). E nesse percurso de construção do conhecimento também deve estar presente o desenvolvimento de novas modalidades tecnológicas de ensino desta temática.

Este estudo apenas instigou algumas discussões sobre o ensino das teorias de enfermagem para acadêmicos do curso de graduação. Desenvolver outros estudos, em realidades diferentes, pode ampliar o conhecimento sobre a visão dos alunos acerca do processo de ensino-aprendizado desta temática, e contribuir para um entendimento maior sobre o mesmo, além de fornecer elementos que favoreçam a identificação de melhores estratégias de ensino. 
As instituições de ensino, assim como os docentes de cursos de enfermagem devem discutir e rediscutir suas práticas, no sentido de identificar os "obstáculos didáticos" (RODRIGUES; SOBRINHO, 2008) em sua prática pedagógica e avançar em busca de atender as necessidades de aprendizagem do futuro enfermeiro, contribuindo ainda mais para a formação de um profissional capacitado a atender a população em diferentes áreas de atuação. 
Revista Eletrônica do Curso de Pedagogia do Campus Jataí - UFG 


\section{REFERÊNCIAS}

BRASIL. CONSELHO NACIONAL DE SAÚDE. RESOLUÇÃO 196/96; Diretrizes e normas regulamentadoras de pesquisa envolvendo seres humanos. Disponível em: $<$ http://conselho.saude.gov.br/docs/Resolucoes/Reso196.doc $>$. Acessado em 310807.

CHINN, P.L; KRAMER, M.K. Theory and nursing: a systematic approach. $4^{\mathrm{a}}$ ed. St. Louis: Mosby, 1995.

FELTRAN, R.C. de Santis (Org.). A prática da docência universitária: São Paulo: Factash, 2003.

FREINET, C. Pedagogia do bom senso: 5a . Ed. - São Paulo: Martins Fontes, 1996.

FREIRE, P. Pedagogia do Oprimido: Rio de Janeiro: Paz e Terra, 2003. . Educação e Mudança. 9ª Ed. Rio de Janeiro: Paz e Terra, 1983.

GANDIN, D. A Prática do Planejamento Participativo: Petrópolis: Ed. Vozes, 1995.

GEORGE J. B. Teorias de enfermagem: Os fundamentos para a prática profissional. Porto Alegre: Artes Médicas, 1993.

KIMURA, M. Teorias de enfermagem - sua aplicação pratica. In: CAMPEDELLI, M.C. et. al. Processo de enfermagem na prática. 2. ed. SP: Editora Ática, 1992. p. 32-33.

MARRINER-TOMEY, A. Nursing theorists and their work: $3^{\text {a }}$ ed. St. Louis: Mosby, 1994.

MARTINS, M. do R.; GOMES, F. V.; NISHIMURA, C. H. Percepção dos discentes acerca das teorias de enfermagem num curso de graduação. Disponível em: < 
http://www.pec.uem.br/pec_uem/revistas/revista\%20APADEC/trabalhos/c6 laudas/MARTINS,\%20Maria\%20d o\%20Rosario.pdf $>$ [doc. PDF on-line] 2004. Acesso em: 10 out. 2008.

NETTINA, S. M. Prática de enfermagem e processo de enfermagem. In: . Pratica de enfermagem. 6. ed. RJ: Guanabara Koogan, 1999.p.05.

MINAYO, M.C.S. (Org.) Pesquisa Social: Teoria, método e criatividade. Petrópolis: Editora Vozes, 1994.

POLIT, D. F; BECK, C.T. HUNGLER, B.P. Fundamentos de pesquisa em enfermagem: métodos, avaliação e utilização. Porto Alegre; Artmed, 2004.

POLIT, D.F.; HUNGLER, B.P. Referenciais teóricos em pesquisa. In: Fundamentos de pesquisa em Enfermagem: 3.ed.Porto Alegre:Artes Medicas, 1995.p.8990

REGO, T.C. Vygotsky. Uma perspectiva Histórico-Cultural da Educação: Rio de Janeiro: Vozes, 1999. 138 p.

RODRIGUES, M.T. P; SOBRINHO, J.A.C.M. Obstáculos didáticos no cotidiano da prática pedagógica do enfermeiro professor: Rev Bras Enferm, v.6, n.4, 2008, p. 435-40.

ROLIM, K.M.C.; PAGLIUCA, L.M.F.; CARDOSO, M.V.L.M.L. Análise da teoria humanística e a relação interpessoal do enfermeiro no cuidado ao recém-nascido: Rev. Latino-am Enfermagem 2005 maio-junho; 13(3): 432-40.

SAUPE, R. A prática pedagógica da(o) docente de graduação em enfermagem: Rev Cienc Saúde. 1993. 12(1): 121-30.

SOUZA, M.F. de. As teorias de enfermagem e sua influência nos processos cuidativos, In: CIANCIARULLO, T.I. et al. Sistema de Assistência de enfermagem: evolução e tendências. 3. ed. SP: Ícone, 2001.p. 36-37. 
STANTON, M.; GEORGE, J.B. Teorias de enfermagem e o processo de enfermagem. In: Teorias de enfermagem. Os fundamentos para a prática profissional. Porto Alegre: Artes Médicas, 1993.p.300.

THOFEHRN, M. B.; LEOPARDI, M. T. Texto \&Contexto enferm: Teorias de Enfermagem, trabalho e conhecimento contemporâneo, Florianópolis, V.1, n 1, p.86-87, jan/abr. 2002.

TORRES, G. A posição dos conceitos e teorias na enfermagem. In: GEORGE, J.B.

Teorias de enfermagem. Os fundamentos para a prática profissional. Porto Alegre: Artes Médicas, 1993.p.17-20. 